\title{
Organ transplantation from deceased donors with cancer: is it safe?
}

This article was published in the following Dove Press journal:

Open Access Surgery

25 July $201 \mathrm{I}$

Number of times this article has been viewed

\author{
Michael A Nalesnik' \\ Michael G Ison² \\ 'Division of Transplantation and \\ Hepatic Pathology, Department of \\ Pathology, University of Pittsburgh \\ Medical Center, Pittsburg, PA, USA; \\ ${ }^{2}$ Divisions of Infectious Diseases and \\ Organ Transplantation, Northwestern \\ University Feinberg School of \\ Medicine, Chicago, IL, USA
}

\begin{abstract}
The availability of donor organs continues to be insufficient to meet the needs of patients actively waiting for transplant. Consequently, there is continuing pressure to increase the donor organ pool while simultaneously assuring safety for the recipient population. The complication of donor malignancy transmission has been documented almost from the beginning of transplantation, and continues to be a concern today. The anecdotal nature of case reports and compiled series ensures that clinical decisions related to organ use from donors with malignancy will of necessity continue to be made on the basis of low-level evidence. Despite this limitation, the literature indicates that not all donor neoplasms have the same risk for transmission to the recipient, and it is necessary to consider the specific malignancy affecting the donor, as well as the condition of the recipient, before a decision is made to transplant or discard a given organ. Published cases suggest that certain forms of neoplasia, such as melanoma, choriocarcinoma, sarcoma, small cell carcinoma, or metastatic carcinomas serve as strong contraindications to organ donation. In contrast, considerable experience exists to suggest that certain tumors of the central nervous system, small subclinical prostate carcinomas, or small renal cell carcinomas resected prior to transplant, among other tumors, should not in themselves disqualify an individual from donating organs in the appropriate circumstance. This review presents the case for considering organ transplantation in the setting of certain donor malignancies and discusses factors to be weighed in such decisions. Additionally, donors with a history of cancer are considered, and features that may aid in reaching a conclusion for or against transplantation of organs from these patients are presented.
\end{abstract}

Keywords: organ transplantation, donor organs, malignancy, complications

\section{Introduction}

Organ transplantation has undergone remarkable progress over the past several decades. However, this major undertaking is by no means risk-free, and among many potential complications, the possibility exists that organ engraftment might be accompanied by the inadvertent transfer of disease, including malignancy, from donor to recipient. This problem has been acknowledged since the early days of modern transplantation ${ }^{1-4}$ and a system of checks and balances has evolved over the years to ensure that such events are rare. Nevertheless, isolated episodes of tumor transmission continue to occur, usually accompanied by significant morbidity or mortality, and often attracting the glare of negative publicity, potentially distorting public perception regarding transplantation in general. Because the supply of donor organs continues to be inadequate to meet current patient needs, ${ }^{5}$ increased attention is being devoted to "high-risk" donors, including those with existing or historical malignant disease.
Correspondence: Michael A Nalesnik Division of Transplantation and Hepatic Pathology, Room E738, UPMC Montefiore Hospital, 3459 5th Avenue, Pittsburgh, PA I5213, USA

Tel + I 4126472094

Fax + I 4I206475237

Email nalesnikma@upmc.edu 
Herein we will consider the issue of organ transplant from potential donors with malignancy. At the outset we distinguish donor-transmitted tumors from donor-derived tumors. ${ }^{6}$ The latter would include, for example, posttransplant lymphoproliferative disorders of donor cell origin, or late-onset neoplasms that arise from allografted donor cells. In post-transplant lymphoproliferative disorders, the process is entirely post-transplant and no tumor existed in the donor. In the case of late-onset tumors (such as 10 years post-transplant), estimated tumor doubling times suggest that no mass lesion existed at the time of transplant. Therefore, tumor development, albeit donor-derived, proceeded entirely or almost entirely in the post-transplant period. Unfortunately, there is no convenient lower time limit by which one can segregate these cases from those in which a small tumor may have been present at transplant and therefore transmitted with the organ. For convenience, we will consider donor-origin tumors arising within a 2 -year post-transplant period as most likely representing donor-transmitted tumors.

It is not our intent to present a comprehensive listing of tumors, because several reports have provided this perspective. ${ }^{7,8}$ Rather, we will provide a general background and discuss some of the more commonly encountered tumor types. Broadly accepted consensus statements regarding donor malignancy screening, cancer transmission risk and recipient selection issues, and optimum screening and management of recipients at risk for or with donor-transmitted cancer are needed, but do not yet exist. For now, we ask the reader to reflect on his or her own position in such situations.

\section{General considerations}

It should be obvious that there is no single correct answer to the question posed in the title of this article. Rather, every donor-recipient combination presents a unique set of circumstances that challenges the transplant surgeon to formulate a sound clinical plan. Specific information regarding both the donor tumor and issues of recipient concern should be obtained. Some suggested items to consider are listed in Table 1.

When considering the possibility of utilizing organs from a donor with known malignant disease, two obvious general questions are first, whether the organs should be used at all, and second, to whom they should be offered.

The first question requires, among other things, that the risk of transmission should be evaluable. The level of evidence on which to base this estimate is low, based mainly on anecdotal reports and collected series. Unfortunately, it is likely to remain in that form for some time to come due to the nature of the subject. Regardless, experience has shown that some tumor types appear to be associated with a high transmissibility rate which, although not precisely definable, is sufficient to defend the position that patients with such tumors (eg, melanoma, sarcoma, metastatic carcinoma) are currently not eligible to serve as organ donors. ${ }^{7-11}$

The second question also requires clinical judgment based on a near absence of high level evidence. Specifically, one must balance both the risk of transmission and the associated morbidity and mortality of tumor development against the estimated life expectancy on the waiting list and likelihood of receiving another offer of a donor organ from a nontumorbearing donor. Prognostic scores, such as the Model for End-stage Liver Disease ${ }^{12}$ and its pediatric counterpart or their more recent variants ${ }^{13}$ may be useful to estimate shortterm survival in potential liver recipients. Analogous efforts have been put forth to predict survival in renal transplant candidates. ${ }^{14,15}$

For those recipients who do develop cancer, widely available statistical data ${ }^{16}$ may provide a starting point for survival estimates. However, a recent study has indicated that stage-specific outcomes for individual cancers may be worse in transplant patients compared with the general population, ${ }^{17}$ and this should factor into the decision-making process.

Table I Items to consider in the setting of a potential organ donor with active or historical neoplasia

\begin{tabular}{ll}
\hline Donor-related & What is the specific type of tumor? \\
& What is the extent of tumor, ie, tumor stage? \\
Historical tumor & What is the risk of the above and also: \\
& How long ago did the tumor occur? What is the tumor-free interval? \\
Recipient- & Is this tumor associated with late recurrence? What is the expected 5-year disease-free survival? \\
related & What type of post-transplant screening would be appropriate in this circumstance? For how long? \\
& What treatment options are available if tumor is transferred? \\
& What are the alternatives for this patient if transplantation is deferred because of concerns about tumor transmission?
\end{tabular}


Given these complexities, the final decision whether or not to utilize any organ in a particular circumstance must ultimately remain a clinical one, made by the transplant surgeon in combination with an informed patient.

\section{Frequency of malignancy in the donor population}

Several reports have estimated the frequency of donor malignancies in various settings. Birkeland and Storm ${ }^{18}$ estimated an overall 1.3\% frequency in a Danish populationbased study of 626 donors. However, that study aggregated both post-transplant living donor tumors and historical tumors, along with those found at the time of donation, and the actual risk of donor tumor present and undetected at time of transplant was $2 / 626$ or $0.3 \%$. Myron Kauffman et $\mathrm{al}^{6}$ estimated a donor frequency rate of $0.04 \%$ based on a cohort of 34,933 cadaveric donors. Because this study relied on voluntary reporting by transplant centers, the possibility of underreporting must be considered. Nevertheless, both studies point to a frequency of unexpected donor malignancy of much less than $1 \%$ of the donor population.

These numbers should be considered in the context of several qualifications. First, the donor selection process typically excludes many individuals with various underlying conditions, including malignancies. Therefore, these figures, which represent our best estimates as based on actual donor populations, may not reflect the incidence of unexpected neoplasia in the general population. Sens et al ${ }^{19}$ performed a retrospective review of 412 mainly forensic autopsies and found unexpected cancer in 29 patients $(7.0 \%)$. Although 12 of these 29 patients had other obvious conditions that would preclude organ donation, the authors estimated that $17(4.1 \%)$ were presumably able to serve as organ donors.

Second, general population figures may provide insight into the overall magnitude of the problem, but the possibility of neoplasia in any given donor should be evaluated in light of the appropriate reference population. For example, Yin et al, ${ }^{20}$ looking at a cohort of 340 male donors, found prostate cancer in one of 203 donors 49 years of age or younger, but that number rose to 40 cancers in 137 donors when those older than 49 were considered.

The decision to use selected donors with cancer would theoretically be expected to have a small but measurable impact on the wait list, which is at 72,169 (active wait list) at the time of writing in March 2011. ${ }^{21}$ The most recent US figures (for the year 2007) showed 2,424,000 deaths, ${ }^{22}$ of which 559,650 were cancer-related..$^{23}$ In the same year, there were 8085 deceased donors who provided organs for 22,056 transplants. ${ }^{24}$ If one makes the assumption that all organs from donors with cancer were declined, then there was approximately one deceased donor per 464 (noncancer) deaths. Applying this ratio to all cancer deaths would lead to an additional 1206 donors, and approximately 3290 additional transplants. This significantly overestimates the actual number of potential additional donors, given that many of these patients would be ineligible to provide organs. (A counterargument is that patients with cancer might be more inclined to serve as organ donors if given the opportunity, resulting in a higher rate of donation for eligible members of this group.) Nevertheless, even if $10 \%$ of such patients were able to donate organs, several hundred additional organ transplants might be performed annually.

\section{Donor tumor transmission risk stratification and recipient safety}

There have been several organized efforts at incorporating experience regarding donor tumor transmission risk into guidelines, policy, or resource documents. The Spanish National Transplant Organization ${ }^{25}$ and the Italian National Transplant $\mathrm{Center}^{26}$ defined separate guidelines for assessing donors with malignancies, among other conditions. In 2009 the Council of Europe published a Guide to Safety and Quality Assurance for the Transplantation of Organs, Tissues and Cells, which included an addendum dealing specifically with criteria to apply in the case of donor malignancy. ${ }^{7}$

In the US, publications from the Organ Procurement and Transplantation Network/United Network for Organ Sharing (OPTN/UNOS) and the Israel Penn International Transplant Tumor Registry (IPITTR) have served to advise practice, in addition to the formal OPTN donor screening and reporting (Policy 4) requirements. Recently, the ad hoc Malignancy Subcommittee of the OPTN Disease Transmission Advisory Committee (DTAC) has published a resource document in which six risk categories for tumor transmission are defined and populated with specific tumor types. ${ }^{8}$

The approach in European countries has also recommended specific cancer screening for donors. At this time in the US, specific screening tests for cancer, beyond assessment by history and examination at time of organ assessment, are not mandated. In an individual with no obvious tumor or history of tumor, questions such as test sensitivity and specificity, time involved, determination of which cancers to screen for and in whom, and plan of action in response to a positive screening test, would all require consensus 
approaches to minimize the effects of false positive and false negative results. ${ }^{27}$

\section{Specific tumor types Central nervous system tumors}

In 2010 the American Cancer Society recorded 22,020 new cases of central nervous system tumors, with an estimated 13,140 deaths in the US. Earlier summaries of tumor registry reports by Penn and Buel1 ${ }^{9,28-30}$ concluded that, in light of the unmet patient need, organs from donors with central nervous system malignancies should not categorically be rejected, but should be offered to recipients with limited short-term life expectancy. This position was further qualified by their conclusion that the presence of prior ventriculoperitoneal shunt, craniotomy, chemotherapy, radiotherapy, or a high grade lesion (specifically medulloblastoma, astrocytoma grades III or IV, ie, glioblastoma multiforme) served as risk factors for transmission and would disqualify potential donation to even this limited recipient pool.

The World Health Organization (WHO) has recently updated the histologic classification of central nervous system tumors which distinguishes high grade (grades 3-4) from low grade (grades 1-2) lesions. ${ }^{31}$ Review of the literature of donor transmission of central nervous system tumors is problematic because, in addition to possible statistical bias, many reports either combine high and low grade tumors ${ }^{32,33}$ or aggregate all primary central nervous system tumors without specifying tumor type. ${ }^{34}$ Further, total numbers of organs or recipients from the given donor(s) are often not provided, hindering efforts at frequency estimates, and additional cofactors such as surgical interventions are not reported in a uniform fashion.

With these limitations in mind, we recently reviewed the literature and found reports concerning 85 donors with glioblastoma multiforme (Grade IV astrocytoma) of whom six were associated with a total of nine transmissions. ${ }^{8}$ This occurred on a background of 145 reported organs transplanted into 142 reported recipients. These numbers represent minimum estimates because not all organs or recipients were explicitly stated in all reports. Other high grade tumors specifically reported included medulloblastoma (26 donors, four of whom were responsible for a total of six tumor transmissions in a minimum estimate of 53 organs transplanted into 43 recipients), malignant meningioma (one donor with transmission), and pineoblastoma and anaplastic ependymoma (one donor each, no transmissions). Low grade tumors included meningioma (21 donors with no transmission in a minimum of 35 reported recipients). Several reports of astrocytomas combined WHO categories I-III, with one transmission reported from a total of 70 donors who provided a minimum of 122 organs to 99 reported recipients.

Other issues may complicate decisions regarding triage of organs from donors with tumors involving the central nervous system. Penn ${ }^{35}$ originally pointed out the necessity to distinguish primary from metastatic central nervous system tumors, with donors from the latter category almost guaranteed to have circulating tumor cells capable of being transmitted. This may be a particular issue with such tumors as choriocarcinoma or renal cell carcinoma.

In 2009, the European Union adopted the WHO classification to segregate donor central nervous system tumors into three groups. ${ }^{7}$ Donors with WHO grades I or II central nervous system tumors are considered eligible to donate organs. Donors with WHO Grade III tumors could be considered in emergency cases and with recipient consent, provided that other risk factors for transmission are absent. Donors with Grade IV central nervous system tumors are ineligible for organ donation, although the possibility of using such organs in case of "vital emergency" and with recipient consent was left open. More recently, the Malignancy Subcommittee of the DTAC committee of OPTN/UNOS ${ }^{8}$ took a similar but slightly more simplified approach, in which donors with WHO grade I or II central nervous system tumors were considered at low risk for transmission, and suggested that such organs may be usable for recipients at significant risk without transplant. In contrast, donors with high grade (WHO III or IV) central nervous system tumors, or any central nervous system tumor with shunt, surgery other than uncomplicated biopsy, radiation, or metastases outside of the central nervous system were considered at high risk for tumor transmission, and use of organs from these donors was discouraged except in rare and extreme circumstances. However, the subcommittee acknowledged the fact that in some cases current opinion may overestimate the risk of transmission. Thus, prospective data collection is needed to determine more definitively the actual transmission rates of individual tumors, and future updates should reflect the best available data.

\section{Renal cell carcinoma}

In the US, the American Cancer Society estimated 58,240 new cases of kidney and renal pelvis cancer, with an estimated 13,040 deaths. ${ }^{16}$ Approximately $80 \%$ of these cases are due to renal cell carcinoma. Inadvertent transfer of renal carcinoma along with the renal allograft was among the earliest examples of malignancy transmission. ${ }^{1-3}$ Penn $^{36,37}$ summarized the early experience, and originally recommended that such 
organs not be used for transplant. However, based on later experience he recommended that if small renal tumors could be excised completely, then the organ could be transplanted provided the patient was carefully followed for possible recurrence. ${ }^{35}$ The limited literature consists of examples of living kidney donors who had small renal tumors at the time of transplantation, ${ }^{38-42}$ series of deceased donors, ${ }^{43}$ or both living and deceased donors ${ }^{44}$ with such tumors. These reports support the position that resection of kidney tumor with subsequent kidney transplantation is compatible with long-term disease-free recipient survival, although the possibility of reporting bias must be borne in mind when considering retrospective anecdotal reports. Most recently, Brook et $\mathrm{al}^{45}$ reported a series of 43 renal transplant recipients who received organs from living donors with renal tumors less than $3 \mathrm{~cm}$ in diameter, and resected prior to transplant. They report one recurrence at 9 years and observed survival similar to that of conventional renal transplantation. These authors recommend this procedure for patients who would otherwise be unable to receive a transplant.

In a recent review of the OPTN/UNOS data, Ison and Nalesnik $^{46}$ observed that in many instances in the US, deceased donor kidneys with small renal cell carcinomas were discarded and, in many cases, the contralateral kidney was discarded as well. However, in 75 patients who did receive organs (usually a liver or the contralateral kidney) from such donors, there have been no reports of malignancy in any recipient. Follow-up time has been limited to 45 days (recently expanded by policy to 2 years) post-transplant, a factor that must be taken into consideration.

\section{Prostate carcinoma}

The American Cancer Society estimates 217,730 new cases of prostate cancer in the US in $2010 .{ }^{16}$ Worldwide, the GLOBOCAN2008 Project of the International Agency for Research on Cancer estimated 899,000 new cases of prostate cancer in 2008, with the highest incidence (104.2 per 100,000) in the Australia/New Zealand region. ${ }^{47}$

Risk of tumor development is age-dependent, with the American Cancer Society estimating a 2\%, 6\%, and $8 \%$ risk of cancer in white males, and a $4 \%, 10 \%$, and $11 \%$ risk in black males, in the 50-59, 60-69 and 70-79 year ranges, respectively. These figures are of concern, given the increasing use of elderly donors. In an evaluation of prostate glands from 340 organ donors, Yin et $\mathrm{al}^{20}$ found adenocarcinoma in a total of 41 (12\%) donors, with $23.4 \%$ in the $50-59,34.7 \%$ in the $60-69$, and $45.5 \%$ frequency in the 70-81 year ranges.
Despite these figures, donor-associated prostate adenocarcinomas have only rarely been reported, with the original report by Loh et $\mathrm{al}^{48}$ frequently cited in the literature. The donor in that case had carcinoma extending into the seminal vesicles with metastases to the pelvic lymph nodes and adrenal glands (Stage IV), discovered after heart transplant had begun.

Kauffman et $\mathrm{al}^{49}$ reported three organs transplanted from donor(s) with prostate carcinoma, with no evidence of transmission, based on the OPTN/UNOS database. A more recent report from the UNOS DTAC covering the years 2005-2009 showed five donors with prostate carcinoma, with no reports of confirmed malignancy transmission. ${ }^{50}$ Pretagostini et al, ${ }^{51}$ reporting for the Italian Centro Nazionale Trapianti, found carcinoma of the prostate to be the commonest donor malignancy in their series, and reported no tumor transmission in organs recovered from three donors with in situ to intermediate degree tumors. They considered high degree prostate carcinoma a contraindication to transplant, but did not provide definitions of these terms.

In light of the near absence of case reports of donor associated prostate carcinomas despite increased use of elderly donors, it seems likely that small incidental prostate carcinomas restricted to the gland have extremely limited risk for transmission via standard organ transplantation. The same cannot be said for more advanced/metastatic tumors, although it would be presumptuous to be dogmatic with limited evidence. It seems prudent to examine the area at the time of organ removal and consider biopsy only of suspicious masses involving the prostatic region or beyond. However, at present, there is no compelling evidence to recommend routine biopsy of the prostate at the time of organ donation (ie, in the absence of a palpable lesion), especially since frozen section may have decreased sensitivity in detection of malignancy, Gleason score, and presence of extracapsular extension. ${ }^{52}$

\section{Melanoma}

Transmission of melanoma by organ transplantation has been documented a number of times since the original report of Jeremy et al. ${ }^{53}$ The IPITTR series reported disease in 17 of 20 recipients who had received organs from donors with generally unsuspected melanoma. ${ }^{54}$ In this patient group, it was pointed out that donor melanoma often masqueraded as a primary central nervous system tumor or unexplained intracranial hemorrhage. An update of this series in the context of cardiothoracic transplantation again concluded that melanomas have a high rate of transmission with subsequent high recipient morbidity and mortality. ${ }^{55}$ 
The American Cancer Society has estimated 68,130 new cases of skin melanomas in 2010, and many of these will have been excised while the tumor is relatively small. Questions regarding potential organ donation in such cases remain unanswered. However, several factors should be considered. First, tumor thickness values do not represent discrete thresholds of tumor progression, and the correlation of thickness to risk of metastatic disease represents a continuous variable. ${ }^{56}$ Second, not only tumor thickness, but also mitotic rate, can lead to upstaging of a melanoma. Since this is a recently introduced modification to the American Joint Cancer Committee staging system, ${ }^{56}$ it is possible that a tumor previously considered as stage Ia is actually stage $\mathrm{Ib}$. Third, Mocellin et $\mathrm{al}{ }^{57}$ conducted a metaanalysis that showed $32 \%$ of stage I melanomas already demonstrated circulating tumor cells; indeed, one study showed circulating melanoma cells in a proportion of patients with stage 0 (in situ) melanoma, ${ }^{58}$ and circulating benign nevus cells have also been identified, ${ }^{59}$ raising the possibility that this might be a characteristic of melanocytes in general. Such findings, of unknown clinical significance at present, urge caution in this area.

A separate issue relates to patients with a history of remote or "cured" melanoma. We are again limited to anecdotal information that indicates that even melanomas $<1 \mathrm{~mm}$ thickness have a small risk of ultra late ( $>15$ years) recurrence. ${ }^{60}$ Hypothetically, this may reflect a prolonged equilibrium between small numbers of circulating tumor cells and the donor host immune system. ${ }^{11}$ Also hypothetically, this balance may dissipate in the setting of organ transplantation and immunosuppression. As circumstantial evidence, transmission of melanoma has been documented at $16^{61}$ and $32^{62}$ years after curative resection in individual cases. In the first case, the original tumor was $2.6 \mathrm{~mm}$ thick, and in the second case size was not reported.

At present it seems reasonable to conclude, as others have done, that any patient with invasive melanoma should not serve as an organ donor. Further, there is no clear evidence to indicate that potential donors with in situ melanoma are not without risk. Because risk of tumor transmission extends to patients with a remote history of melanoma, skin examination for scars that may indicate past curative resection, and close attention to questions regarding previous removal of suspicious skin lesions, are important parts of the donor screening process. These steps are particularly important in the setting of donors with presumed central nervous system hemorrhage, because such lesions may mask underlying metastatic melanoma.
The issue of donor melanoma transmission has recently been reviewed in depth by Strauss and Thomas, ${ }^{11}$ who also concluded that any patient with active or remote "cured" melanoma should not serve as an organ donor.

\section{Special considerations for donors with benign tumors}

Although benign tumors by definition lack the malignant potential of fully developed cancer, several points are worth noting. First, such tumors may be present in the donor organ itself, raising questions of suitability. There are several case reports of successful transplantation of livers with giant hemangiomas, with or without resection in individual cases. ${ }^{63-67}$ In contrast, the use of donor hearts containing benign atrial myxomas is questioned by some authors, ${ }^{6-70}$ and indeed, primary benign tumors themselves may provide a reason for heart transplantation..$^{71,72}$

Other benign tumors have the potential to undergo malignant transformation, and this should be kept in mind when such tumors are encountered. For example, some hepatocellular adenoma subtypes (particularly beta-catenin-expressing ${ }^{73}$ ) have a significant risk of hepatocellular carcinoma, and some typically benign tumors of nontransplant organs, such as salivary gland pleomorphic adenoma, bladder paraganglioma or adrenal pheochromocytoma, may evolve into malignant tumors. Renal oncocytomas and angiomyolipomas may rarely coexist with renal cell carcinoma. Finally, some benign lesions may be confused with malignancies. One such example is adrenal heterotopia occurring on the renal capsule, where the possibility of misdiagnosis as renal cell carcinoma exists. Any of the above circumstances has the potential to lead to nonoptimal triage of donor organs.

\section{Potential donors with a history of cancer}

OPTN/UNOS data on past history of cancer in potential organ donors in the US were first summarized and later updated by Kauffman et al..$^{49,74,75}$ Overall, a total of 1069 donors provided 2508 organs. Of those tumors that were specified, the ten resulting in the most frequent organ allografts (number of transplants in parentheses) included nonmelanoma skin cancer (776), uterine cervical cancer (336), glioblastoma multiforme (175), astrocytoma (152), melanoma (140), breast cancer (126), meningioma (80), ovarian carcinoma (75), prostate carcinoma (66), and endometrial carcinoma (65) ${ }^{74}$ The only reported tumor transmission involved a donor with a history of melanoma 32 years prior, with transmission in one of six organ recipients. It is 
not clear whether this represents the patient later reported by Bajaj et al. ${ }^{62}$

Although the absolute frequency of tumor transmission from this donor cohort is low, the limitations of the data must be kept in mind. The grades and stages of tumors were not reported, and in many cases the specific diagnosis of tumor type itself was not available. The possibility of underreporting also exists, and the authors expressed concern regarding the use of donors with a history of tumors that may exhibit late recurrence, such as lymphoma or carcinomas arising from the breast, lung, colon, or kidney. They also maintained the position that a history of melanoma represents an absolute contraindication for organ donation. ${ }^{74}$

At present, reference to disease-free survival figures provides the best surrogate marker that a cancer may have been "cured"; survival figures alone do not incorporate information regarding rate of recurrence but may represent the only available information in some cases.

Feng et $\mathrm{al}^{10}$ used low frequency of tumor recurrence and high survival as surrogate markers in their discussion of donors with a history of breast or colon carcinoma. They concluded that potential donors with a history of either breast or colon carcinoma in situ (stage 0) could provide organs without any disease-free waiting period, but donors with a history of stage 1 (T1-T2) colon cancer would require a variable disease-free interval, or may never be able to serve as donors, depending upon differences in tumor recurrence and survival rates based on gender and race. In the case of stage 1 breast carcinoma, patients with T1a or T1b cancer could donate after a 10 -year wait period, whereas those with tumor stage T1c or higher would not be eligible to donate regardless of wait period. ${ }^{10}$

The DTAC Malignancy Subcommittee ${ }^{8}$ considered any individuals with a history of melanoma, leukemia, lymphoma, or small cell carcinoma to be ineligible to serve as organ donors. In the case of a history of treated cancer (outside of central nervous system tumors), they suggested a 5 -year wait period, with those patients having a greater than $99 \%$ chance of cure being considered low risk, and those with a probability of cure between $90 \%$ and $99 \%$ considered intermediate risk. Those patients with cure probabilities below these cutoffs, or with insufficient evidence on which to base a conclusion, were considered high risk donors.

\section{Management-related issues}

It is beyond the scope of this article to examine specific management issues in the setting of donor-transmitted neoplasia, and discussion is limited to a few brief points.
First, it is important to report any event in which donortransmitted malignancy is suspected, even if it is not yet proven. The OPTN requires reporting of such events to the OPTN Disease Transmission Advisory Committee, which can facilitate dissemination of information to those involved in the care of other recipients of organs or tissues from the same donor (http://optn.transplant.hrsa.gov/ members/committeesDetail.asp?ID=95). Reporting can be done through UNetSM (https://portal.unos.org/). This committee can provide general discussion related to assessing the likelihood that a given tumor represents a donor origin tumor, as well as recipient evaluation and management, on request. Expertise in this area also exists at the Israel Penn International Transplant Tumor Registry (http://www.ipittr. org/Home.htm).

Patient outcome is dependent upon tumor type, among other things. Kauffman et $\mathrm{al}^{76}$ reviewed OPTN data to estimate $46 \%$ overall mortality from donor transmitted tumors. However, that estimate represents six deaths in 15 recipients, with four of six deaths due to melanomas. A more recent review $^{50}$ of OPTN donor tumor transmission data for the period 2005-2007 inclusive also found six recipient deaths, with four of six due to lymphoma. This suggests that a small number of tumor types contribute disproportionately to recipient mortality.

Conversion to rapamycin or other mammalian target of rapamycin (mTOR) inhibitor has been suggested in the setting of post-transplant malignancy. ${ }^{77-79}$ The immunosuppressed status of the recipient must also be taken into account if chemotherapeutic drugs are considered, and disease-specific survival for several tumor types is worse in the transplant population than in nontransplant patients with similar tumors matched for stage. ${ }^{17}$ For these reasons, oncologic consultation is generally advisable.

\section{Summary}

Potential organ donors with active or historical cancer comprise a heterogeneous population that cannot be evaluated for donation a priori. High level evidence is difficult to come by in this area; nevertheless extensive experience has shown that organs from individuals with metastatic carcinoma, sarcoma, melanoma, or small cell carcinoma should probably never be used for transplant. In contrast, patients with primary central nervous system tumors, prostate carcinoma, or small renal cell carcinomas must be assessed on an individual basis, and the literature documents numerous recipients with successful outcomes who have received organs donated by individuals with these conditions. 
The possibility of cancer should be entertained in every donor, particularly in unusual settings such as unexplained central nervous system hemorrhage, which may mask primary or metastatic malignancy. ${ }^{80}$ Evaluation of such donors requires an objective assessment of the tumor parameters along with a realistic evaluation of transmission risk potential and a monitoring and treatment strategy for the post-transplant period. Parallel evaluation of the recipient is essential, and includes consideration of the urgency of transplant as well as the active participation, consent, and understanding of the recipient regarding the overall risks and benefits.

The question originally raised by the title can be answered by applying the fundamental precept, primum non nocere, and recalling that harm may be avoided either by withholding a dangerous organ, or by performing a life-saving transplant using an organ that best clinical judgment says is appropriate to use in that circumstance.

\section{Disclosure}

The authors report no conflicts of interest in this work.

\section{References}

1. Kuss R, Legrain M, Mathe G, Nedey R. Epilogue on a renal homotransplantation from sister to non-twin brother. Presse Med. 1960;68:1473. French.

2. Martin DC, Rubini M, Rosen VJ. Cadaveric renal homotransplantation with inadvertent transplantation of carcinoma. JAMA. 1965;192: $752-754$.

3. McIntosh DA, McPhaul JJ, Peterson EW, Harvin JS, Smith JR, Humphreys JW Jr. Homotransplantation of a cadaver neoplasm and a renal homograft. JAMA. 1965;192:1171-1173.

4. McPhaul JJ, McIntosh DA. Tissue transplantation still vexes. $N$ Engl J Med. 1965;272:105.

5. Klein AS, Messersmith EE, Ratner LE, Kochik R, Baliga PK, Ojo AO. Organ donation and utilization in the United States, 1999-2008. Am J Transplant. 2010;10(4 Pt 2):973-986.

6. Myron Kauffman H, McBride MA, Cherikh WS, Spain PC, Marks WH, Roza AM. Transplant tumor registry: Donor related malignancies. Transplantation. 2002;74(3):358-362.

7. Coucil of European Publishing. Guide to Safety and Quality Assurance for the Transplantation of Organs, Tissues and Cells. 3rd ed and addendum, 2009. Strasbourg, Germany: Council of Europe Publishing; 2009.

8. Nalesnik MA, Woodle ES, DiMaio JM, et al. Donor transmitted malignancies in organ transplantation: Assessment of clinical risk. Report of the ad hoc Donor Malignancy Subcommittee of the OPTN/UNOS Disease Transmission Advisory committee (DTAC). Am J Transplant. 2011;11(6):1140-1147.

9. Buell JF, Gross T, Alloway RR, Trofe J, Woodle ES. Central nervous system tumors in donors: Misdiagnosis carries a high morbidity and mortality. Transplant Proc. 2005;37(2):583-584.

10. Feng S, Buell JF, Chari RS, DiMaio JM, Hanto DW. Tumors and transplantation: The 2003 Third Annual ASTS State-of-the-Art Winter Symposium. Am J Transplant. 2003;3(12):1481-1487.

11. Strauss DC, Thomas JM. Transmission of donor melanoma by organ transplantation. Lancet Oncol. 2010;11(8):790-796.
12. Freeman RB Jr, Wiesner RH, Roberts JP, McDiarmid S, Dykstra DM, Merion RM. Improving liver allocation: MELD and PELD. Am J Transplant. 2004;4 Suppl 9:114-131.

13. Asrani SK, Kim WR. Organ allocation for chronic liver disease: Model for end-stage liver disease and beyond. Curr Opin Gastroenterol. 2010; 26(3):209-213.

14. Pham PT, Pham PA, Pham PC, Parikh S, Danovitch G. Evaluation of adult kidney transplant candidates. Semin Dial. 2010;23(6):595-605.

15. Van Walraven C, Austin PC, Knoll G. Predicting potential survival benefit of renal transplantation in patients with chronic kidney disease. CMAJ. 2010;182(7):666-672.

16. American Cancer Society Cancer Facts and Figures 2010. Available from: http://www.cancer.org/Research/CancerFactsFigures/index. Accessed May 4, 2011.

17. Miao Y, Everly JJ, Gross TG, et al. De novo cancers arising in organ transplant recipients are associated with adverse outcomes compared with the general population. Transplantation. 2009;87(9):1347-1359.

18. Birkeland SA, Storm HH. Risk for tumor and other disease transmission by transplantation: A population-based study of unrecognized malignancies and other diseases in organ donors. Transplantation. 2002;74(10):1409-1413.

19. Sens MA, Zhou X, Weiland T, Cooley AM. Unexpected neoplasia in autopsies: Potential implications for tissue and organ safety. Arch Pathol Lab Med. 2009;133(12):1923-1931.

20. Yin M, Bastacky S, Chandran U, Becich MJ, Dhir R. Prevalence of incidental prostate cancer in the general population: A study of healthy organ donors. J Urol. 2008;179(3):892-895.

21. United Network for Organ Sharing. Available from: http://www.unos. org/index.php. Accessed March 14, 2011.

22. Table 78. Live births, deaths, marriages, and divorces: 1960-2007. Available from: http://www.census.gov/compendia/statab/2011/ tables/11s0078.pdf. Accessed March 15, 2011.

23. American Cancer Society. Cancer Facts and Figures 2007. Atlanta, GA: American Cancer Society, Inc; 2007 Available from: http:// www.cancer.org/Research/CancerFactsFigures/CancerFactsFigures/ caff2007pwsecured-pdf. Accessed March 11, 2011.

24. HRSA Health Resources and Services Administration; OPTN Organ Procurement and Transplantation Network. Available from: http://optn. transplant.hrsa.gov/latstData/rptData.asp. Accessed May 4, 2011.

25. Garrido G, Matesanz R. The Spanish National Transplant Organization (ONT) tumor registry. Transplantation. 2008;85(8 Suppl):S61-S63.

26. Nanni Costa A, Grossi P, Gianelli Castiglione A, Grigioni WF. Quality and safety in the Italian donor evaluation process. Transplantation. 2008;85(8 Suppl):S52-S56.

27. Schroder FH, Hugosson J, Roobol MJ, et al. Screening and prostatecancer mortality in a randomized European study. $N$ Engl J Med. 2009;360(13):1320-1328.

28. Buell JF. Use of donors with central nervous system malignancies: Proceed with caution (letter). Transplantation. 2004;77(12):1906-1907.

29. Buell JF, Trofe J, Sethuraman G, et al. Donors with central nervous system malignancies: Are they truly safe? Transplantation. 2003;76(2): 340-343.

30. Penn I. Questions about the use of organ donors with tumors of the central nervous system. Transplantation. 2000;70(1):249-250.

31. Louis DN, Ohgaki H, Wiestler OD, Cavanee WK, editors. WHO Classification of Tumours of the Central Nervous System. 4th ed. Lyon, France: International Agency for Research on Cancer; 2007.

32. Chui AK, Herbertt K, Wang LS, et al. Risk of tumor transmission in transplantation from donors with primary brain tumors: An Australian and New Zealand registry report. Transplant Proc. 1999; 31(1-2):1266-1267.

33. Kashyap R, Ryan C, Sharma R, et al. Liver grafts from donors with central nervous system tumors: A single-center perspective. Liver Transpl. 2009;15(10):1204-1208.

34. Kauffman HM, McBride MA, Cherikh WS, Spain PC, Delmonico FL. Transplant tumor registry: Donors with central nervous system tumors. Transplantation. 2002;73(4):579-582. 
35. Penn I. Transmission of cancer with donor organs. Transplant Proc. 1988;20(5):739-740.

36. Penn I. Transplantation of kidneys containing primary malignant tumors. Transplantation. 1973;16(6):674-675.

37. Penn I, Starzl TE. Malignant tumors arising de novo in immunosuppressed organ transplant recipients. Transplantation. 1972;14(4):407-417.

38. Ghafari A. Transplantation of a kidney with a renal cell carcinoma after living donation: A case report. Transplant Proc. 2007;39(5): $1660-1661$.

39. Mannami M, Mannami R, Mitsuhata N, et al. Last resort for renal transplant recipients, 'restored kidneys' from living donors/patients. Am J Transplant. 2008;8(4):811-818.

40. Neipp M, Schwarz A, Pertschy S, Klempnauer J, Becker T. Accidental transplantation of a kidney with a cystic renal cell carcinoma following living donation: Management and 1 yr follow-up. Clin Transplant. 2006; 20(2): 147-150.

41. Sener A, Uberoi V, Bartlett ST, Kramer AC, Phelan MW. Living-donor renal transplantation of grafts with incidental renal masses after ex-vivo partial nephrectomy. BJU Int. 2009;104(11):1655-1660.

42. Whitson JM, Stackhouse GB, Freise CE, Meng MV, Stoller ML. Laparoscopic nephrectomy, ex vivo partial nephrectomy followed by allograft renal transplantation. Urology. 2007;70(5):1007, e1001-e1003.

43. Nicol DL, Preston JM, Wall DR, et al. Kidneys from patients with small renal tumours: A novel source of kidneys for transplantation. BJU Int. 2008;102(2):188-192.

44. Buell JF, Hanaway MJ, Thomas M, et al. Donor kidneys with small renal cell cancers: Can they be transplanted? Transplant Proc. 2005; 37(2):581-582.

45. Brook NR, Gibbons N, Johnson DW, Nicol DL. Outcomes of transplants from patients with small renal tumours, live unrelated donors and dialysis wait-listed patients. Transpl Int. 2010;23(5):476-483.

46. Ison MG, Nalesnik MA. An update on donor-derived disease transmission in organ transplantation. Am J Transplant. March 28, 2011. [Epub ahead of print].

47. Globocan. Globocan 2008 Cancer Fact Sheet: Prostate Cancer Incidence and Mortality Worldwide in 2008. Lyon: Globocan; 2008. Available from: http://globocan.iarc.fr/factsheets/cancers/prostate.asp. Accessed March 11, 2011.

48. Loh E, Couch FJ, Hendricksen C, et al. Development of donor-derived prostate cancer in a recipient following orthotopic heart transplantation. JAMA. 1997;277(2):133-137.

49. Kauffman HM, McBride MA, Delmonico FL. UNOS Transplant Tumor Registry: Donors with a history of cancer. Transplant Proc. 2001;33(1-2):1844-1845.

50. Ison MG, Hager J, Blumberg E, et al. Donor-derived disease transmission events in the United States: Data reviewed by the OPTN/ UNOS Disease Transmission Advisory Committee. Am J Transplant. 2009;9(8):1929-1935.

51. Pretagostini R, Peritore D, Fiaschetti P, et al. Incidence of neoplastic donors in Organizzazione Centro Sud Trapianti area during the 2003-2005 period. Transplant Proc. 2007;39(6):1746-1748.

52. Falconieri G, Rocco M, Angione V, Pizzolitto S. Intraoperative examination for suspected prostatic carcinoma: Frozen sections in "marginal" (cadaveric) transplant donors. Pathol Res Pract. 2009; 205(3):175-182.

53. Jeremy D, Farnsworth RH, Robertson MR, Annetts DL, Murnaghan GF. Transplantation of malignant melanoma with cadaver kidney. Transplantation. 1972;13(6):619-620.

54. Penn I. Malignant melanoma in organ allograft recipients. Transplantation. 1996;61(2):274-278.

55. Buell JF, Trofe J, Hanaway MJ, et al. Transmission of donor cancer into cardiothoracic transplant recipients. Surgery. 2001;130(4): 660-666.

56. Edge SB, Byrd DR, Compton CC, Fritz AG, Greene FL, Trotti A III, editors. AJCC Cancer Staging Manual. 7th ed. New York, NY: Springer Science and Business Media; 2010.
57. Mocellin S, Hoon D, Ambrosi A, Nitti D, Rossi CR. The prognostic value of circulating tumor cells in patients with melanoma: A systematic review and meta-analysis. Clin Cancer Res. 2006;12(15): 4605-4613.

58. Palmieri G, Ascierto PA, Perrone F, et al. Prognostic value of circulating melanoma cells detected by reverse transcriptase-polymerase chain reaction. J Clin Oncol. 2003;21(5):767-773.

59. De Giorgi V, Pinzani P, Salvianti F, et al. Circulating benign nevus cells detected by ISET technique: Warning for melanoma molecular diagnosis. Arch Dermatol. 2010;146(10):1120-1124.

60. Tsao H, Cosimi AB, Sober AJ. Ultra-late recurrence (15 years or longer) of cutaneous melanoma. Cancer. 1997;79(12):2361-2370.

61. MacKie RM, Reid R, Junor B. Fatal melanoma transferred in a donated kidney 16 years after melanoma surgery. $N$ Engl J Med. 2003;348(6):567-568.

62. Bajaj NS, Watt C, Hadjiliadis D, et al. Donor transmission of malignant melanoma in a lung transplant recipient 32 years after curative resection. Transpl Int. 2010;23(7):e26-e31.

63. Aucejo FN, Ortiz WA, Kelly D, et al. Expanding the donor pool: Safe transplantation of a cadaveric liver allograft with a $10 \mathrm{~cm}$ cavernous hemangioma - a case report. Liver Transpl. 2006;12(4):687-689.

64. Mor E, Boccagni P, Thung SN, et al. Backtable resection of a giant cavernous hemangioma in a donor liver. Transplantation. 1995; 60(6):616-617.

65. Nikeghbalian S, Kazemi K, Salahi H, et al. Transplantation of a cadaveric liver allograft with right lobe cavernous hemangioma, without back-table resection: A case report. Transplant Proc. 2007; 39(5):1691-1692.

66. Onaca N, Mizrahi S, Bar Nathan N, Burstein I, Mor E. Liver transplantation after backtable resection of giant hemangioma. Liver Transpl. 2005;11(7):851-852.

67. Pacheco-Moreira LF, Enne M, Balbi E, Santalucia G, Martinho JM. Hemangioma at the liver section plane. Is it a contraindication for living donor liver transplantation? Surgery. 2005;138(1):113.

68. De Boer HD, de Jonge N, de Boer WJ. Mitral valve myxoma: An unusual reason for rejecting a donor heart. J Heart Lung Transplant. 1999; 18(9):924-925.

69. Dufkova B, Malek I, Vymetalova Y, et al. Myxoma of donor origin in a transplanted heart. J Heart Lung Transplant. 2007;26(8): 865-867.

70. Grande AM, Vigano M. Myxoma in a donor heart. Tex Heart Inst J. 2004;31(1):106-107.

71. Gowdamarajan A, Michler RE. Therapy for primary cardiac tumors: Is there a role for heart transplantation? Curr Opin Cardiol. 2000;15(2):121-125.

72. Sharma K, Rohlicek C, Cecere R, Tchervenkov CI. Malignant arrhythmias secondary to a cardiac fibroma requiring transplantation in a teenager. J Heart Lung Transplant. 2007;26(6):639-641.

73. Bioulac-Sage P, Cubel G, Balabaud C, Zucman-Rossi J. Revisiting the pathology of resected benign hepatocellular nodules using new immunohistochemical markers. Semin Liver Dis. 2011;31(1): 91-103.

74. Kauffman HM, Cherikh WS, McBride MA, Cheng Y, Hanto DW. Deceased donors with a past history of malignancy: An organ procurement and transplantation network/united network for organ sharing update. Transplantation. 2007;84(2):272-274.

75. Kauffman HM, McBride MA, Delmonico FL. First report of the United Network for Organ Sharing Transplant Tumor Registry: Donors with a history of cancer. Transplantation. 2000;70(12): 1747-1751.

76. Kauffman MH, McBride MA, Cherikh WS, Spain PC, Marks WH, Roza AM. Transplant tumor registry: Donor related malignancies. Transplantation. 2002;74(3):358-362.

77. Boratynska M, Wattorek E, Smolska D, Patrzalek D, Klinger M. Anticancer effect of sirolimus in renal allograft recipients with de novo malignancies. Transplant Proc. 2007;39(9):2736-2739. 
78. Iaria G, Anselmo A, De Luca L, et al. Conversion to rapamycin immunosuppression for malignancy after kidney transplantation: Case reports. Transplant Proc. 2007;39(6):2036-2037.

79. Manuelli M, De Luca L, Iaria G, et al. Conversion to rapamycin immunosuppression for malignancy after kidney transplantation. Transplant Proc. 2010;42(4):1314-1316.
80. Finger EB, Feng S. Central nervous system tumors and organ donation: An update. Curr Opin Organ Transplant. 2006;11:146-150.
Open Access Surgery

\section{Publish your work in this journal}

Open Access Surgery is an international, peer-reviewed, open access journal that focuses on all aspects of surgical procedures and interventions. Patient care around the peri-operative period and patient outcomes post surgery are key topics. All grades of surgery from minor cosmetic interventions to major surgical procedures are covered. Novel techniques

Submit your manuscript here: http://www.dovepress.com/open-access-surgery-journal

\section{Dovepress}

and the utilization of new instruments and materials, including implants and prostheses that optimize outcomes constitute major areas of interest. The manuscript management system is completely online and includes a very quick and fair peer-review system. Visit http://www.dovepress.com/ testimonials.php to read real quotes from published authors. 